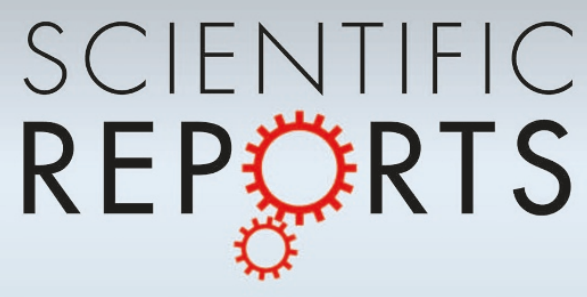

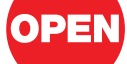

SUBJECT AREAS:

SUSTAINABILITY

MODELLING AND THEORY

ENVIRONMENT

METHODS

Received

29 June 2011

Accepted

7 October 2011

Published

4 November 2011

Correspondence and requests for materials should be addressed to

X.D. (xiaoyue.du@ yale.edu)

\title{
Uncovering the Global Life Cycles of the Rare Earth Elements
}

\author{
Xiaoyue Du \& T. E. Graedel
}

Center for Industrial Ecology, School of Forestry and Environmental Studies, Yale University, New Haven CT 06511.

The rare earth elements (REE) are a group of fifteen elements with unique properties that make them indispensable for a wide variety of emerging, critical technologies. Knowledge of the life cycles of REE remains sparse, despite the current heightened interest in their future availability. Mining is heavily concentrated in China, whose monopoly position and potential restriction of exports render primary supplies vulnerable to short and long-term disruption. To provide an improved perspective we derived the first quantitative life cycles (for the year 2007) for ten REE: lanthanum (La), cerium (Ce), praseodymium $(\mathrm{Pr})$, neodymium $(\mathrm{Nd})$, samarium $(\mathrm{Sm})$, europium $(\mathrm{Eu})$, gadolinium $(\mathrm{Gd})$, terbium $(\mathrm{Tb})$, dysprosium (Dy), and yttrium (Y). Of these REE, Ce and Nd in-use stocks are highest; the in-use stocks of most REE show significant accumulation in modern society. Industrial scrap recycling occurs only from magnet manufacture. We believe there is no post-customer recycling of any of these elements.

he rare earth elements (REE) are a group of metals comprised of yttrium, fourteen lanthanide elements, and sometimes scandium. Their unique physical and chemical properties have rendered them indispensible in a growing number of critical technologies. For example, neodymium is vital to high-performance permanent magnets, and yttrium is a promising raw material for superconductors and laser technology ${ }^{1}$. When these intermediate products are incorporated in final products such as wind turbines, hybrid electric vehicles, or defense applications, REE provide performance that is currently irreplaceable by other materials. These technical innovations have the potential to substantially increase future demand for REE, and trigger global competition for these resources.

As is the case with many materials, but perhaps especially with REE, a comprehensive picture of use and loss is not easy to acquire. Individuals or corporations involved in the life cycle flows of these metals typically know one part of the cycle very well- mining of ore, or purification of metal, or sales of specific products- but not of the entire sequence of acquisition, use, and eventual loss. So far there are only a few studies regarding the cycles and stocks of the $\mathrm{REE}^{2-5}$. Our contribution in the present work is to characterize, albeit rather approximately, the quantity of REE flows through the stages in the whole life cycle, as well as the stocks of REE that currently exist in products providing services.

Since 1990, China has played a dominant role in REE mining; other countries are almost completely dependent upon imports from China with respect to REE resources. China also has become a major REE user in its manufacturing industries. In contrast, a gap in the supply chain has been created in other countries due to diminished manufacturing infrastructure, especially at the critical early phases. China's export restriction of REE raw materials has created a "perfect storm" in which the mining monopoly of China, rapid increases in global REE demand, and Chinese promotion of domestic downstream processing industries come together to make a reliable REE supply to the global market uncertain ${ }^{6-8}$.

Despite the enormous publicity that has recently surrounded the mining and processing of REE, very little quantitative information is available concerning their subsequent life stages, or the separation of REE flows into those of the individual elements. We derive quantitative life cycles herein, using information from published and unpublished sources in China, Japan, the United States and elsewhere, as detailed in references 4 and 5. The results demonstrate how REE are used, retained, and lost, and provide information about the potential for recycling to supplement the production of virgin REE ores.

The principles of mass balance for a metal cycle are shown in Figure 1. The cycle comprises principal stages: mining, separation, fabrication, manufacturing, use and waste? ${ }^{9}$ The stages within the system are linked to each other by flows. Recycling occurs following fabrication for some metals, but not, we believe, for all. Stocks exist as metals that accumulate in each reservoir as a function of time.

The REE occur together in ore deposits with varying concentration distributions. After extraction from the lithosphere, crushing, grinding, flotation, and filter pressing are performed to produce a mixed REE concentrate ${ }^{10}$. 


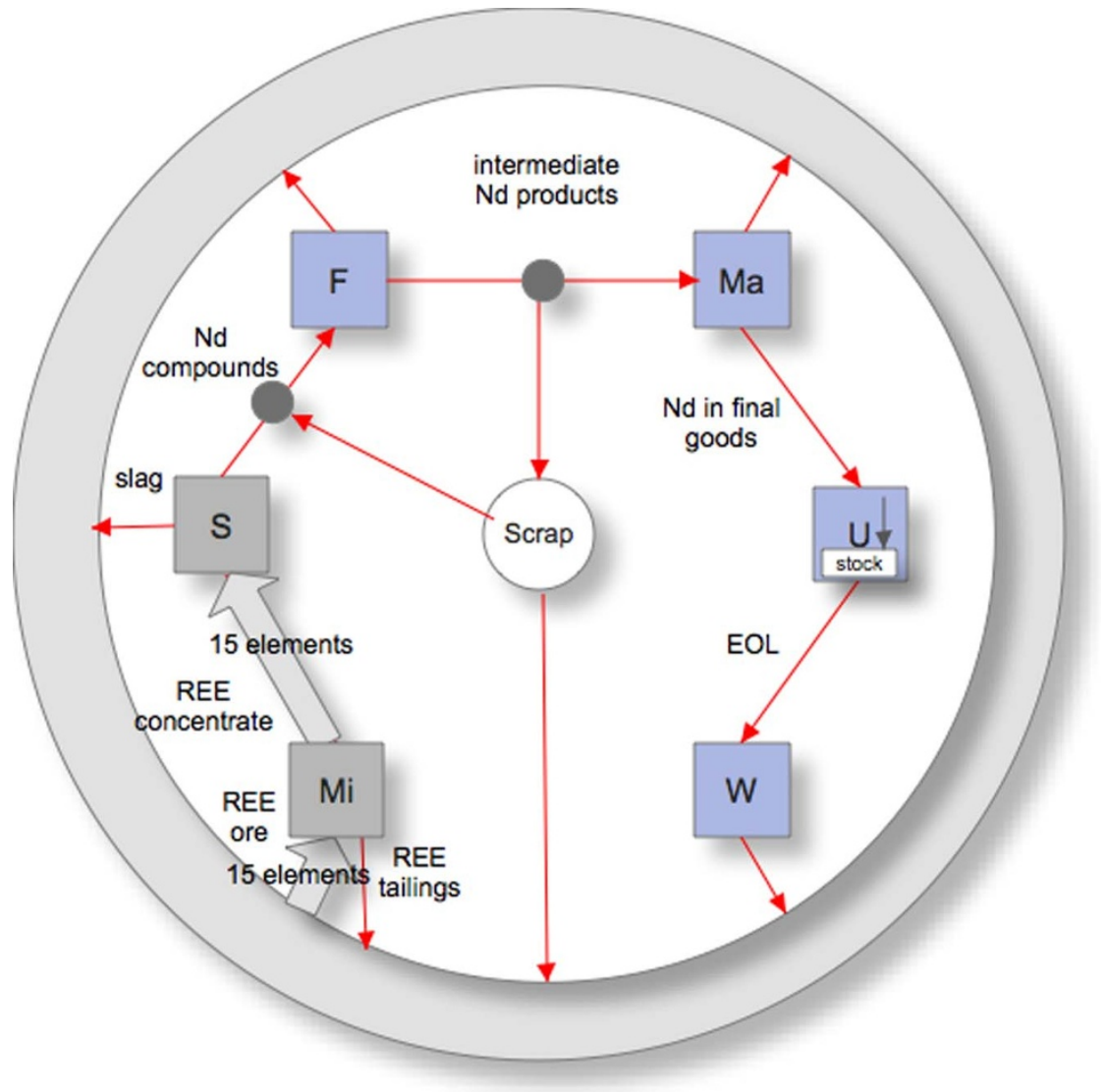

Figure 1 Generic circular flow diagram of a global rare earth element cycle, with neodymium as the example element, where REE is rare earth elements, Mi is mining, $\mathrm{S}$ is separation, $\mathrm{F}$ is fabrication, $\mathrm{Ma}$ is manufacturing, $\mathrm{U}$ is use, EOL is end-of-life, and $\mathrm{W}$ is waste management.

Thereafter, they are separated from each other into individual REE compounds (i.e., oxides, chlorides, fluorides). The compounds are converted into pure metals or alloys and further transformed into intermediate products. Purification of metals is by electrolysis or vacuum reduction ${ }^{11}$. Production of the alloys is either by direct coreduction of the REE compounds or by melting and casting of metals ${ }^{11,12}$. The intermediate products are manufactured into final goods that enter the use phase. Losses occur at each stage. When products containing REE are discarded at the end-of-life (EOL), the quantity of REE material in use is lost unless recycling occurs.

The stocks that exist from extraction through manufacturing are relatively small in magnitude and are transient. In contrast, tailings, in-use stocks, and discards are larger, and continue to accumulate. In-use stocks, in particular, play a crucial role as a growing repository of metal.

Data in this study are from the United States Geological Survey ${ }^{7}$, the Japan Oil, Gas, and Metals National Corporation (JOGMEC) ${ }^{13}$, the Metal Economics Research Institute in Japan ${ }^{14}$, and the China Society of Rare Earths ${ }^{15}$, as well as industries ${ }^{16}$. Relevant literature published in Chinese or Japanese was also extremely helpful ${ }^{17}$. Because the United States was and China now is the main REE producer in the world, analysis of the mining and separation stages relied largely on data from the United States and China.

We were able to locate or derive sufficient information to enable us to construct quantitative global cycles for ten of the REE: lanthanum (La), cerium (Ce), praseodymium (Pr), neodymium $(\mathrm{Nd})$, samarium $(\mathrm{Sm})$, europium $(\mathrm{Eu})$, gadolinium $(\mathrm{Gd})$, terbium $(\mathrm{Tb})$, dysprosium (Dy), and yttrium (Y). Existing data are not sufficient to do so for five seldom-used elements: ytterbium $(\mathrm{Yb})$, holmium (Ho), erbium (Er), thulium (Tm), and lutetium (Lu), nor was sufficient trade data available to enable country-level cycles to be created.

\section{Results}

In 2007, $124.7 \mathrm{Gg}$ of the ten REE were mined globally as ores from the ground and $102.8 \mathrm{Gg}$ of concentrates were produced. The tailings were estimated at $19.2 \mathrm{Gg}$. China produced $97.1 \mathrm{Gg}$ of concentrates from three mining regions: Bayan Obo, Inner Mongolia (57\%); Mianning, Sichuan Province (6\%); and Jiangxi Province $(37 \%)^{15}$. The Chinese production constituted $95 \%$ of the global total. Other REE concentrate producers in 2007 were India $(2.7 \mathrm{Gg})$, Brazil $(0.65 \mathrm{Gg})$, and Malaysia $(0.26 \mathrm{Gg})^{7}$. Although REE have not been mined in the United States since 2001, small amounts (3 Gg) of REE ores previously extracted at Mountain Pass, California were domestically processed in 2007 into La concentrate and didymium, which is a mixture of approximately $75 \% \mathrm{Nd}$ and $25 \% \mathrm{Pr}^{7}$.

The concentrates from these various sources, amounting to 92.5 Gg REE in 2007 were separated into individual REE compounds. The slags generated during the separation stage were $10.3 \mathrm{Gg}$ REE. The compounds were converted into pure metals or alloys and further transformed into intermediate products during the fabrication stage. Losses during fabrication and manufacturing were $9.3 \mathrm{Gg}$ and $83.3 \mathrm{Gg}$. Scrap from some of the elements was recycled and reused within the fabrication stage. The intermediate products were manufactured into final goods containing $90.2 \mathrm{Gg}$ REE.

By aggregating the global production from all the producer countries and disaggregating the values for the individual elements, the cycles for the individual REE can be derived. The results for the individual elements are shown in Figure 2. Note first the example of $\mathrm{La}$. Of the $32.4 \mathrm{Gg} \mathrm{La}$ that was mined in $2007,20 \%$ was lost to tailings at the mining stage. A $10 \%$ loss of the ongoing flow occurred during separation as slag, another $10 \%$ was lost during the fabrication of intermediate products, and another 5\% was lost during the manufacture of most final products. For magnets, however, which undergo multistep processing, Japanese studies indicate about a 
(a)

(c)

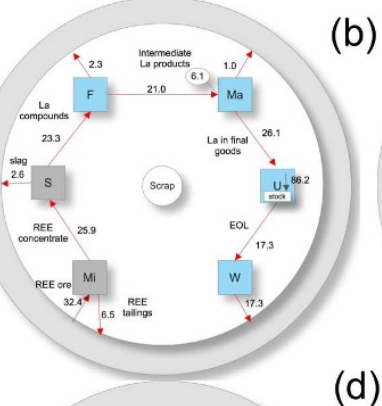

(e)

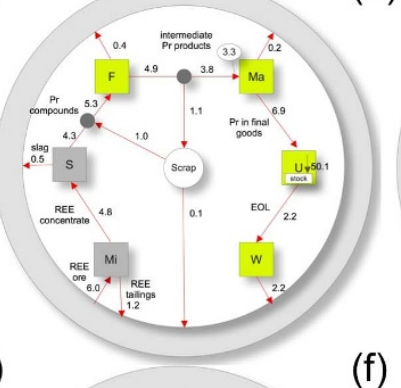

(g)

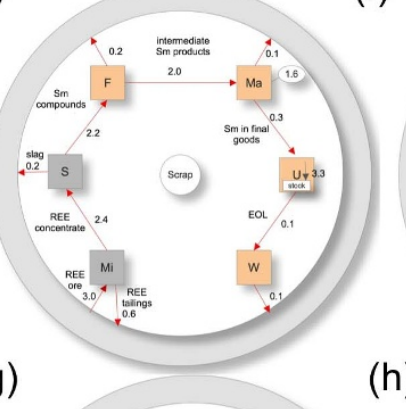

(i)

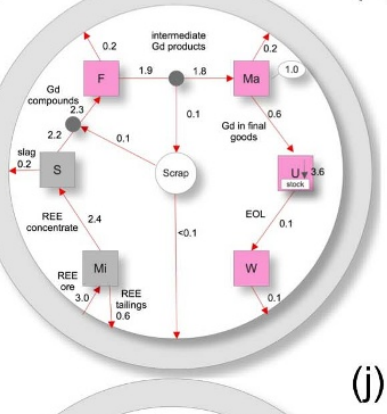

(j)

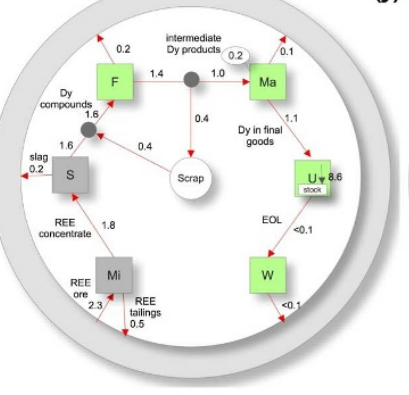

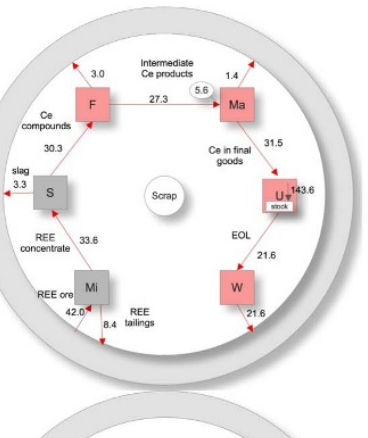

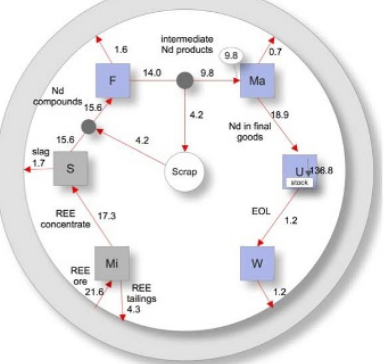

(h)
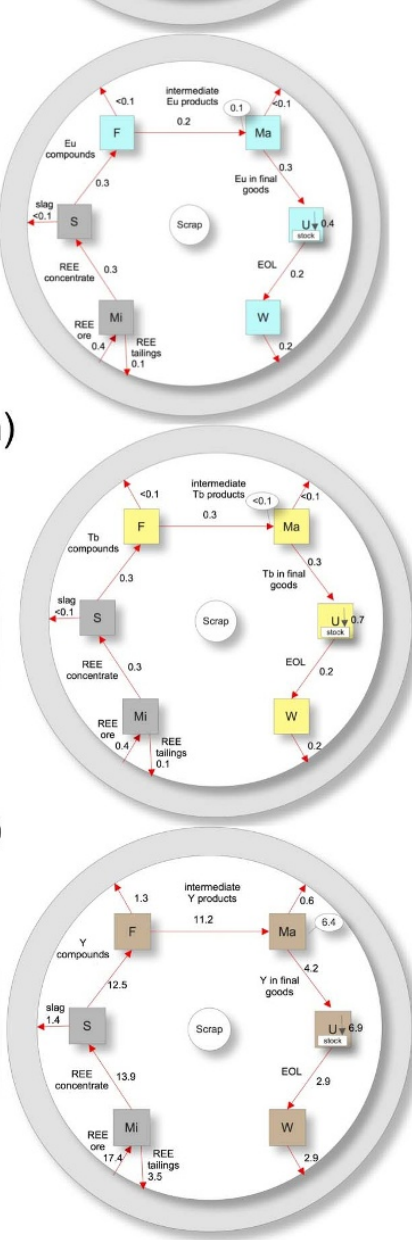

Figure 2 Global material flow cycles for 2007 for (a) lanthanum, (b) cerium, (c) praseodymium, (d) neodymium, (e) samarium, (f) europium, (g) gadolinium, (h) terbium, (i) dysprosium, and $(j)$ yttrium. REE is rare earth elements, $\mathrm{Mi}$ is mining, $\mathrm{S}$ is separation, $\mathrm{F}$ is fabrication, $\mathrm{Ma}$ is manufacturing, $\mathrm{U}$ is use, EOL is end-of-life, and $\mathrm{W}$ is waste management. The circular inflow/outflows to Ma are "phantom flows" discussed in the text. The units are in $\mathrm{Gg}$ (thousand metric tons) of the particular element.

$30 \%$ of the loss rate for $\mathrm{Nd}$ and $\mathrm{Dy}^{2,5}$ in the form of scrap generated in the fabrication and manufacturing stage which was recovered and recycled back into the processes. A "phantom flow" of 5.1 Gg La is required at the manufacturing stage, as $26.1 \mathrm{Gg} \mathrm{La}$ are known to have entered use; this amount is needed to reconcile the discrepancy between reported flows from mining and those reported for flows into use. We do not have sufficient information to resolve their inconsistency, so we retain it and make it apparent as a topic for future work. EOL discards of $17.3 \mathrm{Gg}$ in 2007 are less than flows into use, indicating that in-use stock of $\mathrm{La}$ is accumulating. Estimates show that $86.2 \mathrm{Gg} \mathrm{La}$ accumulated in in-use stock from 1995 to $2007^{18}$. There is no known post-customer recycling of $\mathrm{La}$, so all that is discarded is lost ${ }^{19}$.

As shown in Figure 2, the amounts of individual REE mined from ores in the lithosphere varied from $42 \mathrm{Gg}$ Ce to $0.4 \mathrm{Gg}$ for $\mathrm{Eu}$ and $\mathrm{Tb}$ in 2007. Ce was the REE metal with the largest mining flows (around $34 \%$ of the total), and the total of $\mathrm{Ce}, \mathrm{La}, \mathrm{Nd}$ and Y flows accounted for $91 \%$ of all REE during the mining stage. Outflows as mixed REE concentrates from mining into separation vary from $33.6 \mathrm{Gg}$ Ce to $0.3 \mathrm{Gg} \mathrm{Eu}$ and $\mathrm{Tb}$, with a typical loss of $20 \%$ to tailings and $10 \%$ to slag. The resulting outflows of REE compounds into fabrication ranged from $30.3 \mathrm{Gg}$ Ce to $0.3 \mathrm{Gg}$ Eu and $\mathrm{Tb}$. Fabrication processes resulted in a further $10 \%$ loss ${ }^{9}$. Recycling ranged from $2.85 \mathrm{Gg} \mathrm{Nd}$ to $0.01 \mathrm{Gd}$ during the fabrication stage.

The flows into use are derived from end-use information. The results show flows ranging from $31.5 \mathrm{Gg}$ Ce to $0.3 \mathrm{Gg}$ Eu and $\mathrm{Tb}$. The flows of $\mathrm{La}$ and $\mathrm{Nd}$ are $26.1 \mathrm{Gg}$ and $18.9 \mathrm{Gg}$, respectively, while others are significantly lower. Those for $\mathrm{Pr}$ and $\mathrm{Y}$ are only a few $\mathrm{Gg}$ per year. Annual flows into use in $2007 \mathrm{for} \mathrm{Sm}, \mathrm{Eu}, \mathrm{Gd}, \mathrm{Tb}$ and Dy are at or below $1 \mathrm{Gg} / \mathrm{yr}$ each.

The in-use stocks are derived from knowledge of the product sectors containing REE, when the product constitution of these stocks is known. In-use stocks of ten REE ranged from $143.6 \mathrm{Gg}$ Ce to $0.4 \mathrm{Gg} \mathrm{Eu}$ (16). The Ce stock constituted nearly $33 \%$ of the total. $136 \mathrm{Gg} \mathrm{Nd}, 86 \mathrm{Gg} \mathrm{La}$ and $50 \mathrm{Gg}$ Pr reside in stocks, as do 8.6 Gg Dy, 6.9 Gg Y, 3.3 Gg Sm, 0.7 Gg Tb, and 0.4 Gg Eu.

The flows from EOL included $21.6 \mathrm{Gg}$ Ce and $17.3 \mathrm{Gg} \mathrm{La}$. Between $1 \mathrm{Gg}$ and $3 \mathrm{Gg} \mathrm{Pr}, \mathrm{Nd}$ and $\mathrm{Y}$ went to landfill in 2007. EOL losses for the other five elements were below $1 \mathrm{Gg}$.

\section{Discussion}

The completed cycles demonstrate the opportunities that exist for more efficient use of REE. Losses occur at five points in the cycles: mining, separation, fabrication, manufacturing, and waste management. Improvements in efficiency at any stage, or enhanced efforts at recovery, are important factors in ensuring the long-term availability of REE.

REE stocks are estimated at four times the 2007 annual extraction number, which suggests that REE recycling has the potential to offset a significant part of REE virgin extraction in the future. In addition to mitigating some of the supply risk, recycling could minimize the environmental challenges present in REE mining and processing ${ }^{20-22}$. That said, recycling REE is challenging: it appears possible for metallurgical applications, automobile catalysts, and magnets in wind turbines and automobiles, in which REE are used in fairly large quantities. For other applications, especially where REE are used in small quantities and in complex configurations, the recycling potential is much lower.

As noted above, China currently dominates the mining and processing of virgin REE ores. Corporations and governments seeking to minimize supply risk in the next few years do not have many promising options, but one is to encourage reuse and recycling of REE as the products containing them are discarded. Additionally, designers can attempt to redesign products or minimize REE content if adequate product performance can be maintained. Over the longer term, the likely opening of REE mining in California in the United States $^{22}$ and Mount Weld in Australia ${ }^{23}$ ENREF_21 in the next few years will eventually provide a more geographically dispersed extraction picture. Nonetheless, so long as rates of use continue to increase, 
REE availability, especially for the less abundant REE, will continue to be a challenge. Our results provide general guidance for the potential of in-use stocks to be reused and, thus, to continue providing the unmatched product performance for which REE are known.

\section{Methods}

Material flow analysis serving as a quantitative tool examines flows and stocks of material of interest. The principles of material flow analysis are used in this study, which imply that the mass of total inputs must by definition equal the mass of total outputs plus next accumulation of materials in the system within the processes. Six principal stages are considered in a metal cycle: mining, separation, fabrication, manufacturing, use, and waste management. Flows and stocks are important constituents of the cycle.

The top-down method ${ }^{24}$ was employed to estimate the in-use stocks and EOL flows for individual REE in this study. To satisfy conservation of mass, stock changes in a particular reservoir must equal the difference between all inputs and all outputs over a time span $\left(t_{0}-t\right)$. For a continuous case, the in-use stock is given by the integral equation $^{24,25}$ :

$$
S_{m}(t)=\int_{t_{0}}^{t}\left(\sum_{i} F_{I n, m, i}(t)-F_{\text {Out }, m, i}(t)\right) d t+S_{m}\left(t_{0}\right)
$$

where $S_{m}(t)$ is stock at time $\mathrm{t} ; S_{m}\left(t_{0}\right)$ is stock at time $\mathrm{t}_{0} ; F_{I n, m, I}$ is flow into use of element $m$ in product application $i$; and $F_{\text {Out, } m, I}$ is flow out of use of element $m$ in product application $i$.

A lifetime model was used, based on the assumption that the REE remain in the use stage for the time period of their products' service lives. Each product group has an average service life that can be used to compute these outflows.

1. Angerer, G. et al. Rohstoffe für Zukunftstechnologien: Einfluss des branchenspezifischen Rohstoffbedarfs in rohstoffintensiven

Zukunftstechnologien auf die zukünftige Rohstoffnachfrage. (Fraunhofer IRB Verlag, Stuttgart, 2009).

2. Mineral and Natural Resources Division. 17 species of rare mineral and material flow. (2007).

3. Du, X. \& Graedel, T. E. Global in-use stocks of the rare earth elements: A first stimate. Environmental Science \& Technology (2011).

4. Du, X. \& Graedel, T. E. Global Rare Earth In-Use Stocks in NdFeB Permanent Magnets. Journal of Industrial Ecology, doi:10.1111/j.1530-9290.2011.00362.x (2011).

5. Shi, W., Daigo, I., Matsuno, Y. \& Adachi, Y. Substance flow analysis of Dysprosium in Japan. Journal of Industrial Metals 74, 758-765 (2010).

6. Stone, R. As China's rare earth R\&D becomes ever more rarefied, others tremble. Science 325, 1336-1337, doi:10.1126/science.325_1336 (2009).

7. U.S. Geological Survey. Mineral commodity summaries. Mineral information: Rare Earths. (2008).

8. Schüler, D., Buchert, M., Liu, R., Dittrich, S. \& Merz, C. Study on rare earths and their recycling. (Öko-Institut e.V., Darmstadt, 2011).

9. Reck, B. K., Müller, D. B., Rostkowski, K. \& Graedel, T. E. Anthropogenic nickel cycle: Insights into use, trade, and recycling. Environmental Science \& Technology 42, 3394-3400, doi:10.1021/es072108l (2008).
10. Lynas Corporation. Rare earths: we touch them everyday. (2010).

11. Gupta, C. K. \& Krishnamurthy, N. Extractive Metallurgy of Rare Earths. (CRC Press, 2005).

12. Molycorp Minerals. Global outlook, <http://www.molycorp.com/ globaloutlook.asp > (2009).

13. Japan Oil, Gas and Metals National Corporation. Mineral Resources Material Flow: Rare Earths. (2007).

14. Metal Economics Research Institute. Current trends in the Chinese rare earth industry. (2003).

15. Chinese Society of Rare Earths. Chinese Rare Earth Yearbook 2007. (2008).

16. Lynas Corporation. Presented at ASX Mid Caps Conference. (2010).

17. Liu, Y. \& Xie, L. The global rare earth consumption and prospects. Chinese Rare Earths Vol. 29 (2008).

18. Du, X. \& Graedel, T. E. Global in-use stocks of the rare earth elements: A first estimate. Environmental Science \& Technology 45, 4096-4101, doi:Doi 10.1021/ Es102836s (2011)

19. Graedel, T. E. et al. What do we know about metal recycling rates? Journal of Industrial Ecology 15, 355-366, doi:10.1111/j.1530-9290.2011.00342.x (2011).

20. Bradsher, K. in New York Times (2009).

21. Oakdene Hollins Research and Consulting. Lanthanide Resources and Alternative. (2010)

22. Jacoby, M. \& Jiang, J. Securing the supply of rare earths. Chem Eng News $\mathbf{8 8}, 9-12$ (2010).

23. Kramer, D. Concern grows over China's dominance of rare-earth metals. Physics Today 63, 22-24 (2010).

24. Müller, D. B., Bader, H.-P. \& Baccini, P. Long-term coordination of timber production and consumption using a dynamic material and energy flow analysis. Journal of Industrial Ecology 8, 65-88, doi:10.1162/1088198042442342 (2004).

25. van der Voet, E., Kleijn, R., Huele, R., Ishikawa, M. \& Verkuijlen, E. Predicting future emissions based on characteristics of stocks. Ecological Economics 41, 223234, doi:Doi: 10.1016/s0921-8009(02)00028-9 (2002).

\section{Acknowledgements}

We thank Dr. Ermelinda Harper for reviewing the paper, and support from our colleagues in the Center for Industrial Ecology.

\section{Author contributions}

X.D. designed and performed the study; X.D. and T.E.G. wrote the manuscript; T.E.G. supervised the study.

\section{Additional information}

Competing financial interests: The authors declare no competing financial interests.

License: This work is licensed under a Creative Commons

Attribution-NonCommercial-ShareAlike 3.0 Unported License. To view a copy of this license, visit http://creativecommons.org/licenses/by-nc-sa/3.0/

How to cite this article: Du, X. \& Graedel, T.E. Uncovering the Global Life Cycles of the Rare Earth Elements. Sci. Rep. 1, 145; DOI:10.1038/srep00145 (2011). 